\title{
Dietary exposure to mycotoxins of 1- and 2-year-old children from a Dutch Total Diet Study
}

\author{
A.M. Pustjens ${ }^{1}$, J.J.M. Castenmiller ${ }^{2}$, J.D. te Biesebeek ${ }^{3}$, T.C. de Rijk ${ }^{1}$, R.C.J. van Dam ${ }^{1}$ and P.E. Boon ${ }^{3}$ \\ ${ }^{1}$ Wageningen Food Safety Research (WFSR), Wageningen University and Research, P.O. Box 230, 6700 AE Wageningen, the \\ Netherlands; ${ }^{2}$ Netherlands Food and Consumer Product Safety Authority (NVWA), P.O. Box 43006, 3540 AA Utrecht, the \\ Netherlands; ${ }^{3}$ National Institute for Public Health and the Environment (RIVM), P.O. Box 1, 3729 Bilthoven, the Netherlands; \\ polly.boon@rivm.nl
}

Received: 8 December 2020 / Accepted: 23 March 2021

(c) 2021 Wageningen Academic Publishers

OPEN ACCESS CC (i) RESEARCH ARTICLE

\begin{abstract}
In 2017, a Total Diet Study was conducted in the Netherlands in which mycotoxins were analysed in foods and beverages consumed by 1- and 2-year-old children. These mycotoxins were aflatoxins, Alternaria toxins, citrinin, ergot alkaloids, fumonisins, ochratoxin A, patulin, sterigmatocystin, trichothecenes, and zearalenone. Long-term exposure was calculated by combining concentrations in foods and beverages with consumed amounts of these products. Analysed foods and beverages with a concentration below the detection limit that could contain the mycotoxin, were assigned a concentration equal to half this limit value. To assess if the exposure could result in a possible health risk, the high long-term exposure ( $95^{\text {th }}$ percentile) was compared with a health-based guidance value (HBGV) or a margin of exposure (MOE) was calculated. Exposure to aflatoxins, Alternaria toxins, ochratoxin A and T-2/HT-2 sum may pose a health concern. Foods that contributed most to the exposure of these mycotoxins were bread, biscuits, breakfast cereals, chocolates, dried fruit, follow-on formula and fruit juices.
\end{abstract}

Keywords: dietary exposure, mycotoxins, risk assessment, total diet study, the Netherlands, children

\section{Introduction}

Mycotoxins are chemicals produced by fungi on plants during growth that may cause disease, and even death, in animals and humans after ingestion (EFSA 2011a; (2017b; 2020b). Fungi can also grow on plant products during storage if conditions are favourable. Important mycotoxins that can be present in plant products are produced by Aspergillus, Penicillium, Fusarium and Alternaria species. In 2013, a study on dietary exposure to mycotoxins in the Netherlands showed that the exposure to aflatoxin $\mathrm{B}_{1}\left(\mathrm{AFB}_{1}\right)$, alternariol, alternariol monomethyl ether, ochratoxin A and T-2/HT-2 toxin sum of children 2 to 6 years of age could pose health concerns (Sprong et al., 2016). A recent French study among children 1 and 2 years of age showed a possible health concern regarding the dietary exposure to deoxynivalenol (DON) and T-2/ HT-2 sum (Vin et al., 2020), whereas a 2016 Irish study indicated a potential concern regarding aflatoxin exposure in children 5 to 12 years of age (FSAI, 2016). The European Food Safety Authority (EFSA) has also concluded that the dietary exposure to several mycotoxins, such as aflatoxins (EFSA, 2020d), DON (EFSA, 2017d), T-2/HT-2 sum (EFSA, 2017e) and ochratoxin A (EFSA, 2020b) may pose health concerns.

To assess the risk of dietary exposure to adverse chemicals, such as mycotoxins, dietary exposure to these chemicals can be calculated. This exposure is then compared to a health-based guidance value (HBGV) or used to calculate a margin of exposure (MOE). If the exposure exceeds the HBGV or results in an MOE that is below a critical value, a possible health concern cannot be excluded. To calculate the dietary exposure to chemicals, food consumption data are combined with concentration data of these chemicals in relevant foods. 
In 2017, a total diet study (TDS) was performed in the Netherlands based on food consumption data of the first two years of the Dutch National Food Consumption Survey (DNFCS) of 2012-2016 (A.M. Pustjens et al., unpublished data). In this TDS, foods and beverages consumed by children 1 and 2 years of age were bought, prepared for consumption where applicable and analysed for protein, fat, mycotoxins and (heavy) metals. This age group was selected, because there is limited information on the exposure to chemicals in this age group. Furthermore, young children consume larger amounts per kilogram body weight and may thus be exposed to higher concentrations of chemicals per kilogram body weight compared to adults.

This paper reports on the long-term exposure to mycotoxins of these children based on the analytical results obtained from the TDS. These mycotoxins are aflatoxins, Alternaria toxins, citrinin, ergot alkaloids (ERGOT), fumonisins, ochratoxin A, patulin, sterigmatocystin, trichothecenes, and zearalenone, which have been reported in relation to possible health risks or were detected in at least one of the analysed TDS samples. Exposure was compared with a HBGV or an MOE was calculated to assess possible health risks. Some of the mycotoxins may also have adverse health effects after acute exposure, i.e. exposure on one day (EFSA, 2012b, 2017a,c,d). However, only the long-term exposure was calculated, because concentrations analysed in a TDS are not suitable for assessing acute exposure (EFSA, 2011c).

\section{Materials and methods}

\section{Total diet study}

Selection of foods and beverages included in the TDS and their pooling in composite samples is described elsewhere (A.M. Pustjens et al., unpublished data). In short, foods and beverages were selected from food consumption data of 232 children 1 and 2 years of age (12-35 months) collected on two non-consecutive days during the first two years of the DNFCS of 2012-2016 (van Rossum et al., 2016, 2020). In total, 1,930 foods and beverages were identified, which covered 96-98\% of consumed amounts of all foods and beverages in this age group, and bought in one area (Wageningen and surroundings) between August and November 2017. Foods and beverages were subsequently prepared for consumption where applicable and pooled in 164 composite samples. If pooling in a composite sample could result in a dilution of mycotoxin concentrations, and when the foods and beverages were consumed in relatively high amounts, they were assigned to a separate (individual) composite sample. For example, apple and apple sauce are known sources of patulin and were not included in a combined fruit sample. Composite samples were grouped in 18 food groups and 59 subgroups (Table 1) for three age groups: 12-17 months, 18-23 months, and 24-35 months. In this way, differences in consumed amounts and types of foods and beverages consumed among age groups were addressed in the exposure calculations.

\section{Table 1. Food groups and subgroups included in the total diet study}

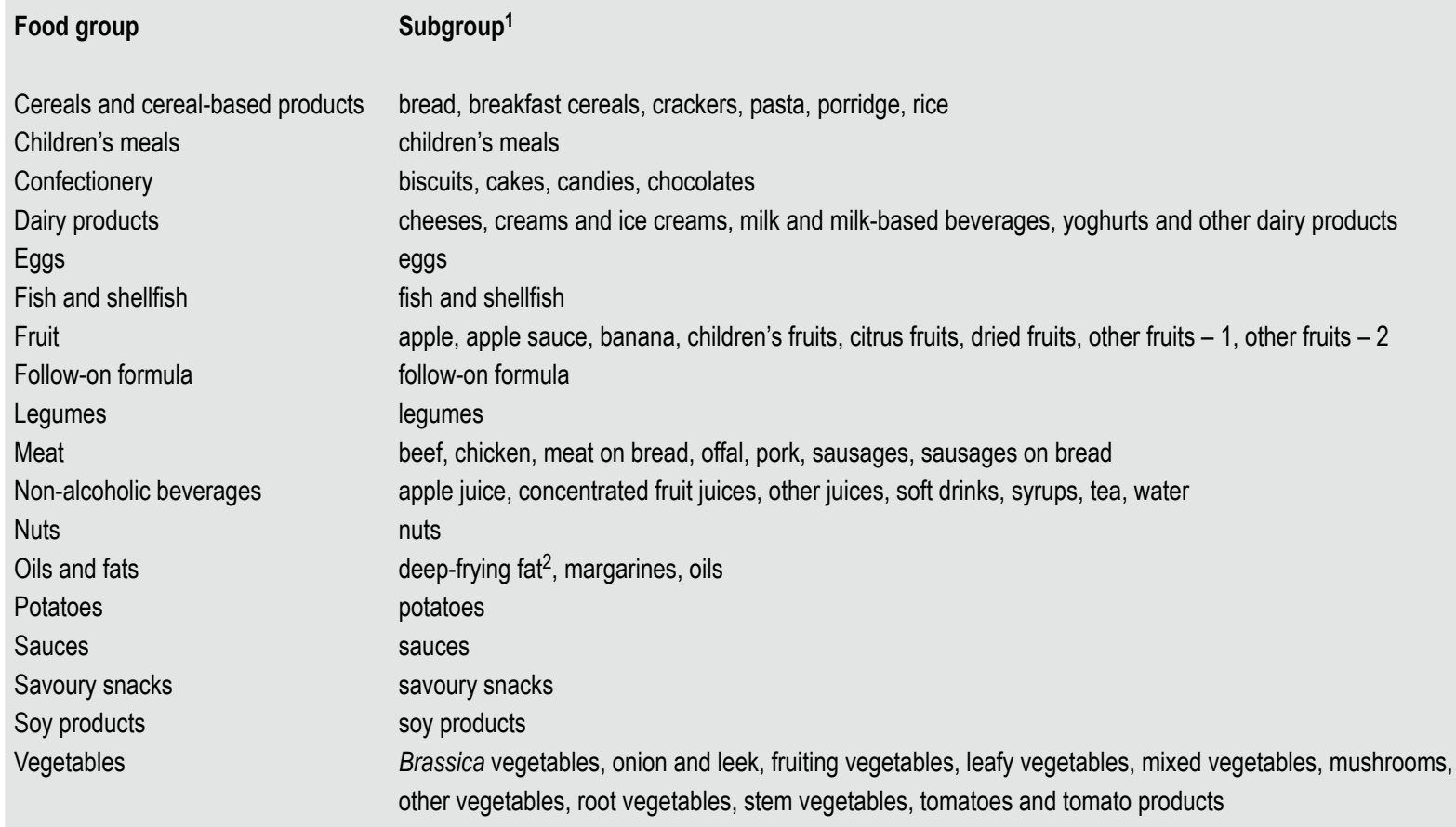

\section{Subgroup ${ }^{1}$}

bread, breakfast cereals, crackers, pasta, porridge, rice

children's meals

biscuits, cakes, candies, chocolates

cheeses, creams and ice creams, milk and milk-based beverages, yoghurts and other dairy products eggs

fish and shellfish

apple, apple sauce, banana, children's fruits, citrus fruits, dried fruits, other fruits -1 , other fruits -2

follow-on formula

legumes

beef, chicken, meat on bread, offal, pork, sausages, sausages on bread apple juice, concentrated fruit juices, other juices, soft drinks, syrups, tea, water

nuts

deep-frying fat ${ }^{2}$, margarines, oils

potatoes

sauces

savoury snacks

soy products

Brassica vegetables, onion and leek, fruiting vegetables, leafy vegetables, mixed vegetables, mushrooms, other vegetables, root vegetables, stem vegetables, tomatoes and tomato products

\footnotetext{
${ }^{1}$ More details about the foods sampled per subgroup are described elsewhere (Pustjens et al., unpublished data).

2 This fat was used to deep fry foods.
} 
Liquid composite samples were frozen immediately after pooling. A portion of 500 gram of all other (solid) composite samples was freeze-dried. All composite samples were stored at $-20^{\circ} \mathrm{C}$ until analysis.

\section{Mycotoxin analysis}

All mycotoxins, except patulin and aflatoxin $M_{1}$, were analysed using a multi-mycotoxin liquid chromatographytandem mass spectrometry (LC-MS/MS) method. Trichothecenes (DON, 3-acetyl-DON (3-ADON), 15-acetylDON (15-ADON), HT-2, nivalenol (NIV), and T-2) were also analysed using a gas chromatography-tandem mass spectrometry (GC-MS/MS) method with lower limits of detection (LODs) than the LODs of the multi-mycotoxin method. These analyses were performed in a subset of the composite samples. This subset was selected based on the analytical results from previous research (López et al., 2016). In addition, $\mathrm{AFB}_{1}$, aflatoxin $\mathrm{B}_{2}\left(\mathrm{AFB}_{2}\right)$, aflatoxin $\mathrm{G}_{1}\left(\mathrm{AFG}_{1}\right)$ and aflatoxin $\mathrm{G}_{2}\left(\mathrm{AFG}_{2}\right)$ were analysed using a dedicated method with lower LODs: an immunoaffinity columns-high performance liquid chromatography-fluorescence detector (IAC-HPLC-FLD) method. Patulin was analysed using a dedicated LC-MS/MS method, and aflatoxin $\mathrm{M}_{1}\left(\mathrm{AFM}_{1}\right)$ using the same IAC-HPLC-FLD method as used to analyse the other aflatoxins in a subset of samples.

All analytical methods were applied as described in López et al. (2016), except for the methods of analysis of patulin and trichothecenes. Both these methods were significantly modified. A description of the analytical methods can be found in Supplementary Materials and methods S1, including performance characteristics (Supplementary Table S1-S3) and the LODs and limits of quantification (LOQs). These limits varied between 0.01 and $400 \mu \mathrm{g} / \mathrm{kg}$ analysed material (Supplementary Table S4).

\section{Mycotoxin concentrations used in exposure calculations}

Mycotoxin concentrations analysed at or above the LOD of the multi-mycotoxin method or the dedicated methods were used as such in the exposure calculation. Mycotoxin concentrations analysed at a value below the LOD were included at a value of $0.5 \times$ LOD (medium bound (MB) scenario) when:

- composite samples were likely to contain the mycotoxin; this was based on an analysis performed by Sprong et al. (2016);

- comparable composite samples of at least one age group had a mycotoxin concentration at or above the LOD.

In all other cases, composite samples with a value below the LOD, the so-called non-detect samples, were assumed not to contain the mycotoxin and concentration was set to zero. For example, none of the 'egg' or 'water' composite samples had a detectable value and also no mycotoxins were expected to be present in these samples (Supplementary Table S5 and S6). A number of mycotoxin concentrations were reported at a value between the LOD and the LOQ of the analytical method (Supplementary Table S5). These values were used as such to calculate exposure.

Table 2 gives an overview of the mycotoxins included in this study. Some of the mycotoxins can be grouped when calculating exposure, because they have the same toxic effect after ingestion (EFSA, 2012b, 2017d, 2018a; Table 2). Concentrations of these mycotoxins were summed per composite sample and these summed concentrations were used to calculate exposure (Table 2). For aflatoxins sum, concentrations were summed as $\mathrm{AFB}_{1}+\mathrm{AFB}_{2}+\mathrm{AFG}_{1}+$ $\mathrm{AFG}_{2}+\left(\mathrm{AFM}_{1} \times 0.1\right) \cdot \mathrm{AFM}_{1}$ concentration was multiplied by a factor of 0.1 as the potency of this mycotoxin is 10 times less than the potency of the other aflatoxins (EFSA, 2020d). For DON sum, ERGOT sum, fumonisins sum and T-2/HT-2 sum, concentrations of the individual mycotoxins per group were summed assuming equipotency. Concentrations of mycotoxins analysed below the LOD in a certain sample were included in the sum either as a zero or at a value of $0.5 \times$ LOD as described above.

\section{Exposure calculations}

Long-term exposure was calculated using the Observed Individual Means (OIM) model as implemented in the calculation tool Monte Carlo Risk Assessment (MCRA) version 8.3 (De Boer et al., 2019). Using the OIM model, a daily consumed amount of a food or beverage of a child was multiplied with the concentration in the relevant composite sample resulting in an exposure for each food or beverage. These exposures were summed to derive the total exposure per day of each child. To obtain a measure for long-term exposure, these daily exposures were averaged over the two days present in the DNFCS for each child, resulting in a distribution of two-day average exposures. Exposures were divided by the child's body weight (bw), which was measured during a home visit. In total, 100 distributions of two-day average exposures were calculated using a bootstrap approach (Efron, 1979; Efron and Tibshirani, 1993). The bootstrap is an accepted methodology to quantify sampling uncertainty in the exposure distribution (EFSA, 2012a, 2018b). For this, 100 food consumption databases were generated by resampling of the original database and each was used to calculate the exposure, resulting in 100 exposure distributions. For each distribution, $50^{\text {th }}$ (median; P50) and $95^{\text {th }}$ (P95) percentiles of exposure were calculated. Median of both percentiles and the $95^{\text {th }}$ uncertainty interval around the percentiles are reported. This uncertainty interval quantifies the uncertainty of the percentiles due to the sample size of the food consumption database. Uncertainty due to the sample size of the concentration database could not be 
Table 2. Mycotoxins included in the total diet study and their toxicological reference values and critical effects. ${ }^{1}$

\begin{tabular}{|c|c|c|c|c|}
\hline \multirow[t]{2}{*}{ Mycotoxin } & \multicolumn{4}{|c|}{ Toxicological reference value } \\
\hline & Type & Value in $\mathrm{ng} / \mathrm{kg}$ bw per day & Critical effects & Reference \\
\hline $\begin{array}{l}\text { AFLs sum }{ }^{2} \\
\text { AFB }_{1} \\
\mathrm{AFB}_{2} \\
\mathrm{AFG}_{1} \\
\mathrm{AFG}_{2} \\
\mathrm{AFM}_{1}\end{array}$ & $\mathrm{BMDL}_{10}$ & 400 & increase of liver carcinomas & EFSA, 2020d \\
\hline $\begin{array}{l}\text { Alternaria toxins } \\
\mathrm{AOH} \\
\mathrm{AME}\end{array}$ & TTC & 2.5 & genotoxicity & EFSA, 2011a \\
\hline BEA & \multicolumn{4}{|c|}{ no toxicological reference value available } \\
\hline CIT & level of no concern & 200 & nephrotoxicity & EFSA, 2012c \\
\hline $\begin{array}{l}\text { ENN B } \\
\text { ENN B } B_{1}\end{array}$ & \multicolumn{4}{|c|}{ no toxicological reference value available } \\
\hline $\begin{array}{l}\text { ERGOT sum } \\
\text { AGR } \\
\text { Ergcor } \\
\text { Ergocrist } \\
\text { Ergocryp } \\
\text { Ergomet } \\
\text { Ergosin } \\
\text { Ergotam }\end{array}$ & TDI & 600 & vasoconstrictive effects & EFSA, 2012b \\
\hline $\begin{array}{l}\text { FBs sum }{ }^{3} \\
\mathrm{FB}_{1} \\
\mathrm{FB}_{2} \\
\mathrm{FB}_{3}\end{array}$ & TDI & 1000 & liver toxicity & EFSA, 2018a \\
\hline OTA & $\mathrm{BMDL}_{10}$ & $\begin{array}{l}4,730 \\
14,500\end{array}$ & $\begin{array}{l}\text { kidney lesions } \\
\text { kidney tumours }\end{array}$ & EFSA, 2020b \\
\hline PAT & PMTDI & 400 & weight gain reduction & JECFA, 1995 \\
\hline STE & $\mathrm{BMDL}_{10}$ & 160,000 & haemangiosarcomas & EFSA, 2013b \\
\hline $\begin{array}{l}\text { DON sum }{ }^{4,5} \\
\text { DON } \\
\text { 3-ADON } \\
\text { 15-ADON }\end{array}$ & TDI & 1000 & weight gain reduction & EFSA, 2017d \\
\hline $\mathrm{NIV}^{4}$ & TDI & 1,200 & reduction white blood cell count & EFSA, 2013a; 2017a \\
\hline $\begin{array}{l}\text { T-2/HT-2 sum } 4 \\
\text { HT-2 } \\
\text { T-2 }\end{array}$ & TDI & 20 & reduction of total leukocyte count & EFSA, 2017c \\
\hline $\begin{array}{l}\text { ZEN sum }{ }^{6} \\
\text { ZEN }\end{array}$ & TDI & 250 & oestrogenic activity & EFSA, 2011b; 2016a; 2017b \\
\hline
\end{tabular}

\footnotetext{
${ }^{1} \mathrm{BMDL}_{10}=$ lower limit of the $95^{\text {th }}$ confidence interval of the estimated dose with a $10 \%$ additional risk; bw $=$ body weight; PMTDI = provisional maximum tolerable daily intake; TDI = tolerable daily intake; TTC = threshold of toxicological concern; $A F L s=$ aflatoxins; $A_{1}, A F B_{2}, A F G_{1}, A F G_{2}, A F M_{1}=$ aflatoxin $B_{1}, B_{2}, G_{1}, G_{2}$ and $\mathrm{M}_{1} ; \mathrm{AOH}=$ alternariol; $\mathrm{AME}$ = alternariol monomethyl ether; $\mathrm{BEA}=$ beauvericin; $\mathrm{CIT}$ = citrinin; $\mathrm{ENN}$ = enniatin; $\mathrm{ERGOT}=$ ergot alkaloids; $\mathrm{AGR}=$ agroclavine; Ergcor = ergocorn(-in)-ine; Ergocrist = ergocrist(-in)-ine; Ergocryp = ergocrypt(-in)-ine; Ergomet = ergometr(-in)-ine; Ergosin = ergos(-in)-ine; Ergotam = ergotam(in)-ine; $F B s=$ fumonisins; $F B_{1}, F B_{2}, F B_{3}=$ fumonisin $B_{1}, B_{2}$ and $B_{3} ; O T A=$ ochratoxin $A ; P A T=$ patulin; $S T E=$ sterigmatocystin; $D O N=$ deoxynivalenol; $A D O N=$ acetyldeoxynivalenol; NIV = nivalenol; T-2 = T-2 toxin; $\mathrm{HT}-2$ = HT-2 toxin; $\mathrm{ZEN}=$ zearalenone.

${ }^{2}$ EFSA (2020d) established a BMDL 10 of $400 \mathrm{ng} / \mathrm{kg}$ bw per day for $\mathrm{AFB}_{1}, \mathrm{AFB}_{2}, \mathrm{AFG}_{1}$ and $\mathrm{AFG}_{2}$, and a relative potency factor of 0.1 for $\mathrm{AFM}_{1}$.

${ }^{3}$ Fumonisin $B_{4}$ is included in the TDI. This mycotoxin was not analysed in this study.

${ }^{4}$ These mycotoxins belong to the group of trichothecenes.

${ }^{5}$ Deoxynivalenol-3-O-glucoside is included in the TDI. This mycotoxin was not analysed in this study.

${ }^{6} \mathrm{a}$-Zearalenol and $\beta$-zearalenol are included in the TDI. These mycotoxins were analysed in this study, but were not included in the exposure calculations (see Materials and methods - exposure calculations).
} 
quantified in this way, because only one concentration per composite sample was available.

Composite samples were also analysed for $\alpha$-zearalenol and $\beta$-zearalenol, two modified forms of zearalenone. These forms have the same mode of action as zearalenone and should thus be considered when calculating exposure to zearalenone (EFSA, 2017b). However, concentrations of both forms were below the LOD in all composite samples. Assigning $0.5 \times$ LOD to relevant composite samples would have resulted in an unrealistically high exposure to zearalenone, because $\alpha$-zearalenol is 60 times more potent for humans than zearalenone. Hence, these forms were not included in the exposure estimate of zearalenone. $\beta$-zearalenol is five times less potent than zearalenone (EFSA, 2017b).

Exposure was calculated for the three age groups and for the total age group of 1- and 2-year olds using the consumed amounts recorded in the DNFCS 2012-2016. Contribution of each food subgroup to the total exposure distribution expressed as a percentage was also calculated for each of the 100 exposure distributions. Mean contribution of these 100 exposure distributions is reported.

\section{Risk characterisation of mycotoxins}

Risk characterisation was performed by comparing P95 exposure estimates with a health-based guidance value (HBGV) or by calculating a margin of exposure (MOE). MOE was calculated by dividing the lower limit of a benchmark dose (BMDL) of a mycotoxin by the P95 exposure estimate. Table 2 lists the HBGVs or BMDLs for each mycotoxin. For beauvericin, enniatin $B$ and enniatin $B_{1}$, no HBGVs or BMDLs are available (EFSA, 2014).

\section{Results}

\section{Concentrations of mycotoxins in composite samples}

In total, 89 (out of $164 ; 54 \%$ ) composite samples did not contain mycotoxins at a concentration at or above the LOD. Remaining 75 composite samples had a detectable concentration for one $(n=26)$ to eight mycotoxins $(n=1)$. The sample with eight mycotoxins was 'pasta' for the oldest age group and mycotoxins detected were alternariol monomethyl ether, two ergot alkaloids (ergocorn(-in)-ine and ergocrist(-in)-ine), enniatin $B$, enniatin $B_{1}, D O N$, nivalenol and HT-2. Mycotoxins with a detectable concentration in at least 10 composite samples were, in descending order, alternariol monomethyl ether $(n=43)$, enniatin $B(n=35)$, alternariol $(n=30)$, DON $(n=26)$, enniatin $B_{1}(n=22), T-2$ $(\mathrm{n}=19)$, ochratoxin A $(\mathrm{n}=18)$, nivalenol $(\mathrm{n}=16)$ and HT-2 $(\mathrm{n}=12)$. Individual concentrations in the composite samples in which at least one mycotoxin had a concentration at or above the LOD are listed in Supplementary Table S5.
Supplementary Table S7 lists minimum and maximum mycotoxin concentrations of the composite samples for each food group. These concentrations ranged from less than $0.001 \mu \mathrm{g} / \mathrm{kg}$ for aflatoxins sum in 'dairy products' to $115 \mu \mathrm{g} / \mathrm{kg}$ for DON sum in 'cereals and cereal-based products.' This concentration for DON sum was measured in 'crackers' of the youngest age group.

For most composite samples, no difference was observed in mycotoxin concentrations among the composite samples per age group within a subgroup, except for DON sum in 'pasta' and for citrinin in 'chicken' and 'fish and shellfish'. In these subgroups, higher concentrations were observed in the composite samples of the oldest age group (Supplementary Table S5).

\section{Exposure and contributions of food groups to the exposure}

P95 exposure estimates were comparable between age groups for aflatoxins sum, alternariol, ERGOT sum, fumonisins sum, nivalenol, sterigmatocystin and zearalenone (Table 3). For the other mycotoxins, P95 estimates of the 18-23 months age group were either higher (alternariol monomethyl ether, beauvericin, ochratoxin A, patulin, and T-2/HT-2 sum) or lower (citrinin, DON sum, enniatin B, and enniatin $B_{1}$ ) than the estimates of the other two age groups.

Table 4 lists percentage contributions of the three subgroups that contributed most to the total exposure distribution for each mycotoxin. Important contributors were:

- cereals and cereal products, such as 'bread', 'pasta', 'porridge' and 'breakfast cereals';

- non-alcoholic beverages, such as 'other juices', 'apple juice' and 'concentrated fruit juices';

- confectionery, such as 'cakes, 'biscuits' and 'chocolates'

For ochratoxin A, 'dried fruits' and 'follow-on formula' contributed most to the exposure.

\section{Comparison with HBGV or calculation of MOE}

Comparison of the P95 exposure estimates of 1- and 2-year olds with the HBGV showed that the exposure to the two Alternaria toxins and T-2/HT-2 sum exceeded the HBGV (Table 5). HBGV was exceeded by a factor of about 20, 50 and 10 for alternariol, alternariol monomethyl ether and T-2/HT-2 sum, respectively. The results of the risk characterisation were also applicable to the P95 exposure estimates of each age group, including the upper limits of the $95 \%$ confidence interval.

For aflatoxins sum, ochratoxin A and sterigmatocystin, an MOE was calculated (Table 5). For aflatoxins, MOE for the P95 exposure was 27, which was far below the MOE of no concern of at least 10,000 (EFSA, 2005). For ochratoxin A, 
Table 3. Long-term exposure to mycotoxins of children 1 and 2 years of age based on concentrations analysed in composite samples. ${ }^{1}$

\begin{tabular}{|c|c|c|c|c|c|c|c|c|}
\hline \multirow[t]{3}{*}{ Mycotoxin } & \multicolumn{8}{|c|}{ Exposure in $\mathrm{ng} / \mathrm{kg}$ body weight per day per age group ${ }^{2,3}$} \\
\hline & \multicolumn{2}{|l|}{ 12-17 months } & \multicolumn{2}{|l|}{ 18-23 months } & \multicolumn{2}{|l|}{ 24-35 months } & \multicolumn{2}{|l|}{1 and 2 years } \\
\hline & P50 & P95 & P50 & P95 & P50 & P95 & P50 & P95 \\
\hline AFLs sum & $3.4(3.2-3.9)$ & $6.6(6.3-7.1)$ & $3.4(2.1-2.4)$ & $6.6(3.4-4.5)$ & $3.6(3.3-3.8)$ & $6.0(5.6-6.5)$ & $3.6(3.4-3.8)$ & $6.4(6.2-6.6)$ \\
\hline $\mathrm{AOH}$ & $21(17-24)$ & $61(43-86)$ & $14(10-17)$ & $39(30-55)$ & $11(8.8-13)$ & $32(27-36)$ & $14(13-16)$ & $42(39-51)$ \\
\hline AME & $18(15-19)$ & $41(36-50)$ & $19(15-23)$ & $138(101-229)$ & $27(22-33)$ & $127(102-157)$ & $21(19-24)$ & $123(96-135)$ \\
\hline BEA & $3.4(2.9-3.8)$ & $9.4(7.8-12)$ & $4.4(3.3-5.5)$ & $20(17-29)$ & $2.9(2.6-3.3)$ & $6.1(5.4-6.7)$ & $3.2(3.0-3.5)$ & $11(10-14)$ \\
\hline CIT & $25(22-28)$ & $56(50-60)$ & $26(22-29)$ & $47(44-53)$ & $27(25-32)$ & $101(81-118)$ & $26(25-27)$ & $73(64-81)$ \\
\hline DON sum & $230(176-254)$ & $572(528-731)$ & $230(200-272)$ & $574(483-624)$ & 209 (183-243) & $750(653-883)$ & 221 (199-238) & 649 (575-749) \\
\hline ENN B & $80(69-104)$ & $226(215-308)$ & 96 (79-117) & $234(212-272)$ & $123(109-147)$ & $466(428-575)$ & $106(93-118)$ & $379(309-450)$ \\
\hline ENN B $_{1}$ & $25(21-32)$ & $69(63-101)$ & $30(25-36)$ & $78(68-94)$ & $42(37-54)$ & $159(130-174)$ & $34(30-39)$ & $119(104-152)$ \\
\hline ERGOT sum & $54(49-67)$ & $140(123-154)$ & $61(47-72)$ & $139(118-145)$ & $54(45-65)$ & $130(108-142)$ & $56(51-63)$ & $140(124-145)$ \\
\hline FBs sum & $98(79-118)$ & $278(260-519)$ & $93(82-126)$ & 254 (217-319) & $75(67-89)$ & $321(243-492)$ & $85(78-93)$ & $291(274-425)$ \\
\hline NIV & $14(12-16)$ & $40(35-48)$ & $15(12-18)$ & $36(30-40)$ & $13(11-16)$ & $36(29-39)$ & $14(12-16)$ & $38(33-40)$ \\
\hline OTA & $5.3(4.6-6.8)$ & $17(15-31)$ & $10(8.6-12)$ & $28(24-30)$ & $3.3(3.0-4.0)$ & $13(10-15)$ & $4.7(4.1-5.8)$ & $22(19-24)$ \\
\hline PAT & $1.2(0.6-1.9)$ & $69(46-102)$ & $1.4(1.0-2.4)$ & $59(27-81)$ & $1.1(0.8-1.7)$ & $43(29-68)$ & $1.2(1.0-1.7)$ & $61(46-79)$ \\
\hline STE & $0.9(0.7-1.1)$ & $2.1(1.9-4.9)$ & $1.0(0.8-1.2)$ & $2.6(2.2-2.7)$ & $0.9(0.9-1.1)$ & $2.0(1.8-2.1)$ & $0.9(0.9-1.0)$ & $2.1(2.0-2.6)$ \\
\hline T-2/HT-2 sum & $21(14-33)$ & $273(195-398)$ & $15(9.0-35)$ & 231 (153-308) & $16(12-22)$ & $185(121-276)$ & $18(13-23)$ & $247(189-304)$ \\
\hline ZEN & $11(9.0-12)$ & $35(25-49)$ & $13(10-16)$ & $36(28-52)$ & $12(11-14)$ & $30(26-36)$ & $12(11-13)$ & $32(28-37)$ \\
\hline
\end{tabular}

${ }^{1} \mathrm{LOD}=$ limit of detection; $\mathrm{P} 50=$ median or $50^{\text {th }}$ percentile; $\mathrm{P95}=95^{\text {th }}$ percentile; $\mathrm{AFLs}=$ aflatoxins; $\mathrm{AOH}=$ alternariol $; \mathrm{AME}=$ alternariol monomethyl ether; $\mathrm{BEA}$ = beauvericin; $\mathrm{CIT}=$ citrinin; $\mathrm{DON}=$ deoxynivalenol; $\mathrm{ENN}=$ enniatin; $\mathrm{ERGOT}$ = ergot alkaloids; FBs = fumonisins; OTA = ochratoxin A; PAT = patulin; STE = sterigmatocystin; NIV = nivalenol; $\mathrm{T}-2$ = $\mathrm{T}-2$ toxin; $\mathrm{HT}-2$ = $\mathrm{HT}-2$ toxin; $\mathrm{ZEN}=$ zearalenone.

${ }^{2}$ Exposures are based on medium-bound concentrations: concentrations of mycotoxins below the LOD in composite samples that could contain the mycotoxin were substituted a value of $0.5 \times$ LOD (see Materials and methods - mycotoxin concentrations used in exposure calculations).

${ }^{3}$ Exposures in brackets are the lower and upper limit of the $95 \%$ confidence interval (see Materials and methods - exposure calculations).

two BMDLs were available resulting in MOEs of 215, related to kidney lesions, and 659, related to kidney tumours. MOE of 215 was above the minimum value of 200 that 'was considered as being of low health concern', whereas the MOE of 659 was far below the minimum value of 10,000 (EFSA, 2020b). MOE for sterigmatocystin was far above the minimum value of 10,000 (Table 5).

\section{Discussion}

\section{Uncertainties in the exposure calculations}

An important uncertainty in the exposure calculations was the non-detect mycotoxin concentrations. In those cases, it is not clear whether the mycotoxin is present at a concentration that cannot be detected, or not at all. To address this uncertainty, typically a lower bound (LB) and upper bound (UB) scenario are calculated. Concentrations below the LOD or LOQ are substituted a value of zero in the LB scenario and a value equal to the LOD or LOQ in the UB scenario. LB and UB exposure estimates provide a lower limit and upper limit of the actual exposure considering the analysed concentrations. In the current study, we used a medium bound $(\mathrm{MB})$ scenario: concentrations below the LOD were substituted a value of $0.5 \times$ LOD if the presence of the mycotoxin could not be excluded; otherwise, we assumed that the mycotoxin was not present and a value of zero was used (see Materials and methods - mycotoxin concentrations used in exposure calculations). The MB scenario was used considering the high number of nondetect samples in our TDS (54\%). Furthermore, we used the reported values for the concentrations between LOD and LOQ instead of assuming a value equal to $0.5 \times \mathrm{LOQ}$. This was relevant for the two Alternaria toxins, DON sum, nivalenol, T-2/HT-2 sum and zearalenone (Supplementary Table S5). Although these values are also uncertain, we considered the reported values better estimates of the actual concentration than $0.5 \times \mathrm{LOQ}$. However, also an $\mathrm{MB}$ scenario can potentially overestimate the exposure to mycotoxins that were not detected in a large number of samples. To examine this, exposure to the five critical mycotoxins (see Results - comparison with HBGV or 
Table 4. Mean contributions (\%) of the three food subgroups contributing most to the total exposure distribution per mycotoxin for children 1 and 2 years of age.

\begin{tabular}{|c|c|c|c|c|}
\hline \multirow[t]{2}{*}{ Mycotoxins $^{1}$} & \multicolumn{4}{|l|}{ Contribution (\%) per age group 2} \\
\hline & $12-17$ months & 18-23 months & 24-35 months & 1 and 2 years \\
\hline \multirow[t]{3}{*}{ AFLs sum } & Bread $(15 \%)$ & Bread $(11 \%)$ & Biscuits (14\%) & Bread $(13 \%)$ \\
\hline & Biscuits (12\%) & Biscuits (10\%) & Bread $(13 \%)$ & Biscuits (12\%) \\
\hline & Breakfast cereals $(12 \%)$ & Breakfast cereals $(9 \%)$ & Chocolates $(9 \%)$ & Chocolates $(7 \%)$ \\
\hline \multirow[t]{3}{*}{$\mathrm{AOH}$} & Children's fruits (19\%) & Other juices (19\%) & Breakfast cereals $(26 \%)$ & Breakfast cereals $(15 \%)$ \\
\hline & Children's meals (12\%) & Children's fruits (18\%) & Other juices (17\%) & Other juices $(15 \%)$ \\
\hline & Other juices (9\%) & Savoury snacks (12\%) & Apple sauce $(10 \%)$ & Children's fruits (14\%) \\
\hline \multirow[t]{3}{*}{ AME } & Candies (18\%) & Other juices (63\%) & Other juices (57\%) & Other juices (53\%) \\
\hline & Chocolate (12\%) & Chocolates $(8 \%)$ & Chocolates $(12 \%)$ & Chocolates (11\%) \\
\hline & Children's meal (11\%) & Margarines $(6 \%)$ & Margarines $(7 \%)$ & Margarines $(6 \%)$ \\
\hline \multirow[t]{3}{*}{ BEA } & Bread $(17 \%)$ & Biscuits (18\%) & Porridge (8\%) & Bread $(14 \%)$ \\
\hline & Tomatoes and tomato products (16\%) & Bread $(17 \%)$ & Cakes $(8 \%)$ & Biscuits (13\%) \\
\hline & Biscuits $(14 \%)$ & Chocolates (11\%) & Biscuits $(7 \%)$ & Tomatoes and tomato products (13\%) \\
\hline \multirow[t]{3}{*}{ CIT } & Bread $(18 \%)$ & Bread $(15 \%)$ & Fish and shellfish (18\%) & Bread (14\%) \\
\hline & Biscuits (14\%) & Biscuits (13\%) & Chicken $(17 \%)$ & Biscuits (14\%) \\
\hline & Breakfast cereals $(14 \%)$ & Breakfast cereals $(12 \%)$ & Biscuits (13\%) & Chicken (13\%) \\
\hline \multirow[t]{3}{*}{ DON sum } & Pasta (31\%) & Pasta (35\%) & Pasta (43\%) & Pasta $(38 \%)$ \\
\hline & Bread (22\%) & Bread $(23 \%)$ & Bread (22\%) & Bread (22\%) \\
\hline & Biscuits (15\%) & Biscuits (14\%) & Biscuits (17\%) & Biscuits (16\%) \\
\hline \multirow[t]{3}{*}{ ENN B } & Pasta $(40 \%)$ & Pasta $(36 \%)$ & Pasta (46\%) & Pasta (43\%) \\
\hline & Bread (17\%) & Bread (16\%) & Bread (24\%) & Bread $(21 \%)$ \\
\hline & Breakfast cereals $(12 \%)$ & Biscuits (11\%) & Biscuits (9\%) & Biscuits $(9 \%)$ \\
\hline \multirow[t]{3}{*}{ ENN B1 } & Pasta $(38 \%)$ & Pasta $(28 \%)$ & Bread (38\%) & Bread (32\%) \\
\hline & Bread $(23 \%)$ & Bread $(22 \%)$ & Pasta $(29 \%)$ & Pasta (30\%) \\
\hline & Nuts $(7 \%)$ & Nuts $(12 \%)$ & Breakfast cereals (8\%) & Nuts $(8 \%)$ \\
\hline \multirow[t]{3}{*}{ ERGOT sum } & Bread $(21 \%)$ & Cheeses $(22 \%)$ & Biscuits (22\%) & Biscuits (20\%) \\
\hline & Biscuits (19\%) & Bread $(18 \%)$ & Bread $(21 \%)$ & Bread $(20 \%)$ \\
\hline & Breakfast cereals (18\%) & Biscuits (17\%) & Cheeses $(17 \%)$ & Cheeses $(16 \%)$ \\
\hline \multirow[t]{3}{*}{ FBs sum } & Soy products $(17 \%)$ & Apple juice (21\%) & Apple juice (20\%) & Apple juice (19\%) \\
\hline & Bread $(14 \%)$ & Bread $(12 \%)$ & Biscuits (16\%) & Biscuits (14\%) \\
\hline & Biscuits (12\%) & Biscuits (11\%) & Bread $(15 \%)$ & Bread $(14 \%)$ \\
\hline \multirow[t]{3}{*}{ NIV } & Bread (34\%) & Bread (31\%) & Bread $(37 \%)$ & Bread $(35 \%)$ \\
\hline & Biscuits (20\%) & Biscuits (19\%) & Biscuits (24\%) & Biscuits $(22 \%)$ \\
\hline & Breakfast cereals (12\%) & Pasta (15\%) & Cakes $(13 \%)$ & Cakes $(11 \%)$ \\
\hline \multirow[t]{3}{*}{ OTA } & Follow-on formula (29\%) & Dried fruits $(35 \%)$ & Other juices (26\%) & Dried fruits (25\%) \\
\hline & Dried fruits $(17 \%)$ & Follow-on formula (26\%) & Dried fruits $(18 \%)$ & Follow-on formula (21\%) \\
\hline & Other juices (16\%) & Other juices (16\%) & Follow-on formula $(12 \%)$ & Other juices $(20 \%)($ \\
\hline \multirow[t]{3}{*}{ PAT } & Concentrated fruit juices (67\%) & Concentrated fruit juices (48\%) & Concentrated fruit juices (53\%) & Concentrated fruit juices (46\%) \\
\hline & Appel juice $(24 \%)$ & Appel juice (40\%) & Appel juice (33\%) & Appel juice (43\%) \\
\hline & Apple (6\%) & Apple (9\%) & Apple (8\%) & Apple (7\%) \\
\hline \multirow[t]{3}{*}{ STE } & Soy products (19\%) & Bread (13\%) & Biscuits (15\%) & Bread (15\%) \\
\hline & Bread $(16 \%)$ & Biscuits (13\%) & Bread $(14 \%)$ & Biscuits (14\%) \\
\hline & Biscuits (13\%) & Breakfast cereals (11\%) & Chocolate $(10 \%)$ & Soy products (10\%) \\
\hline \multirow[t]{3}{*}{ T-2/HT-2 sum } & Other juices (25\%) & Other juices (37\%) & Apple juice (38\%) & Apple juice (36\%) \\
\hline & Concentrated fruit juices $(23 \%)$ & Apple juice (37\%) & Other juices (32\%) & Other juices $(31 \%)$ \\
\hline & Apple juice (22\%) & Concentrated fruit juices (12\%) & Concentrated fruit juices (10\%) & Concentrated fruit juices (13\%) \\
\hline \multirow[t]{3}{*}{ ZEN } & Soy products (16\%) & Chocolates $(28 \%)$ & Chocolates $(25 \%)$ & Chocolates $(23 \%)$ \\
\hline & Bread $(13 \%)$ & Nuts $(21 \%)$ & Nuts $(19 \%)$ & Nuts $(18 \%)$ \\
\hline & Nuts (12\%) & Bread $(9 \%)$ & Biscuits (12\%) & Bread (11\%) \\
\hline
\end{tabular}

\footnotetext{
${ }^{1} \mathrm{AFLs}=$ aflatoxins; $\mathrm{AOH}=$ alternariol; $\mathrm{AME}=$ alternariol monomethyl ether; $\mathrm{BEA}=$ beauvericin; $\mathrm{CIT}=$ citrinin; $\mathrm{DON}=$ deoxynivalenol; $\mathrm{ENN}=$ enniatin; $\mathrm{ERGOT}=$ ergot alkaloids; $\mathrm{FBs}$ = fumonisins; $\mathrm{OTA}$ = ochratoxin $\mathrm{A} ; \mathrm{PAT}$ = patulin; $\mathrm{STE}=$ sterigmatocystin; NIV = nivalenol; T-2 = T-2 toxin; HT-2 = HT-2 toxin; ZEN = zearalenone.

${ }^{2}$ Contributions of the age group of 1 - and 2 -year olds are the summed contributions of the three composite samples per subgroup.
} 
Table 5. Percentage of the health-based guidance values (HBGV) or margins of exposure (MOE) for the P95 long-term exposure to mycotoxins for children 1 and 2 years of age. ${ }^{1}$

\begin{tabular}{|c|c|c|c|}
\hline Mycotoxin & P95 exposure ${ }^{2}$ & HBGV & $\%$ of $\mathrm{HBGV}^{3}$ \\
\hline \multicolumn{4}{|c|}{ in ng/kg body weight per day } \\
\hline $\mathrm{AOH}$ & $42(39-51)$ & 2.5 (TTC) & $1,680(1,560-2,040)$ \\
\hline AME & $123(96-135)$ & & $4,920(3,840-5,400)$ \\
\hline CIT & $73(64-81)$ & 200 (level of no concern) & $37(32-41)$ \\
\hline DON sum & $649(575-749)$ & 1000 (TDI) & $65(58-75)$ \\
\hline ERGOT sum & $140(124-145)$ & 600 (TDI) & $23(21-24)$ \\
\hline FBs sum & $291(274-425)$ & 1000 (TDI) & $29(27-43)$ \\
\hline NIV & $38(33-40)$ & 1,200 (TDI) & $3(3-3)$ \\
\hline PAT & $61(46-79)$ & 400 (PMTDI) & $15(12-20)$ \\
\hline $\mathrm{T}-2 / \mathrm{HT}-2$ sum & $247(189-304)$ & 20 (TDI) & $1,235(945-1,520)$ \\
\hline \multirow[t]{3}{*}{ ZEN } & $32(28-37)$ & 250 (TDI) & $13(11-15)$ \\
\hline & P95 exposure ${ }^{2}$ & $\mathrm{BMDL}_{10}$ & $\mathrm{MOE}^{3,4,5}$ \\
\hline & \multicolumn{2}{|c|}{ in ng/kg body weight per day } & \\
\hline AFLs sum & $6.4(6.2-6.6)$ & 400 & $63(61-65)$ \\
\hline \multirow[t]{2}{*}{ OTA } & $22(19-24)$ & 4,730 & $215(197-249)$ \\
\hline & & 14,500 & $659(604-763)$ \\
\hline STE & $2.1(2.0-2.6)$ & 160,000 & $76,000(62,000-80,000)$ \\
\hline \multicolumn{4}{|c|}{ 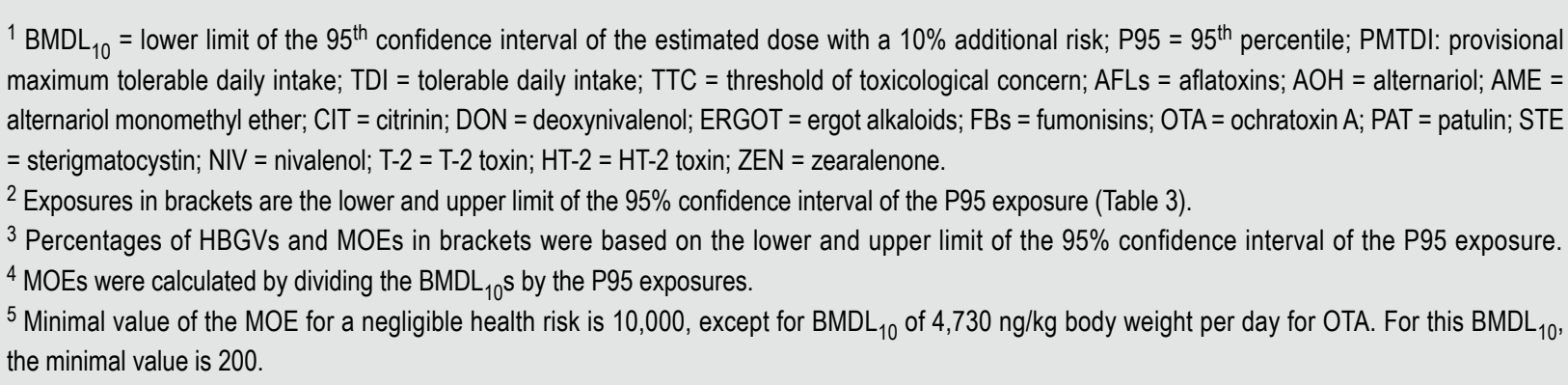 } \\
\hline
\end{tabular}

calculation of MOE) was also calculated according to the LB scenario (Table 6). For aflatoxins sum, the LB exposure was much lower than the $\mathrm{MB}$ exposure, showing that the MB exposure was largely determined by samples with an assigned value of $0.5 \times$ LOD. In addition, in all relevant composite samples, except those belonging to food group 'dairy products' in which only aflatoxin $M_{1}$ could be present (Supplementary Table S6), a value of $0.5 \times$ LOD was substituted for each of the four aflatoxins resulting in the imputation of a concentration equal to $2 \times$ LOD. This imputation resulted in even higher MB exposure estimates. However, this uncertainty did not affect the risk characterisation; also if it is assumed that no aflatoxins are present in the non-detect samples, MOE for the P95 exposure estimate is below the critical value of 10,000 . For the other four critical mycotoxins, exposure estimates decreased less or were not affected in the LB scenario compared to the MB scenario, because the main contributors to their exposure were foods with detectable concentrations (Table 6 and Supplementary Table S7).

Exposure to a number of mycotoxins was grouped, because of a same mode of action after ingestion (see Materials and methods - mycotoxin concentrations used in exposure calculations). For DON sum and fumonisins sum, not all relevant mycotoxins were included. DON sum did not include deoxynivalenol-3-O-glucoside (DON-3G) (Table 2 ). EFSA calculated a ratio of $20 \%$ for the concentration of DON-3G to DON based on concentrations in cereal products (EFSA, 2017d), indicating that exposure to DON sum may have been underestimated. Applying a factor of 1.2 to the P95 exposure estimate resulted in an exposure of about $780 \mathrm{ng} / \mathrm{kg}$ bw per day for the age group of 1 - and 2-year olds. This exposure estimate did not exceed the 
Table 6. Long-term exposure to five mycotoxins that may pose a health risk in children 1 and 2 years of age using lower-bound and medium-bound concentrations in composite samples with a concentration below the limit of detection (LOD). 1

\begin{tabular}{|c|c|c|c|c|}
\hline \multirow[t]{3}{*}{ Mycotoxin } & \multicolumn{4}{|c|}{ Exposure in ng/kg body weight per day ${ }^{2}$} \\
\hline & \multicolumn{2}{|l|}{ P50 } & \multicolumn{2}{|l|}{ P95 } \\
\hline & Lower-bound $^{3}$ & Medium-bound ${ }^{4}$ & Lower-bound $^{3}$ & Medium-bound ${ }^{4}$ \\
\hline AFLs sum & $0(0-0)$ & $3.6(3.4-3.8)$ & $0.3(0.2-0.4)$ & $6.4(6.2-6.6)$ \\
\hline $\mathrm{AOH}$ & $6.7(5.7-9.0)$ & $114(13-16)$ & $36(30-41)$ & $42(39-51)$ \\
\hline AME & $20(19-25)$ & $21(19-24)$ & $124(96-137)$ & $123(96-135)$ \\
\hline OTA & $0.5(0.4-0.6)$ & $4.7(4.1-5.8)$ & $15(12-20)$ & $22(19-24)$ \\
\hline $\mathrm{T}-2 / \mathrm{HT}-2$ sum & $7.2(6.1-8.9)$ & $18(13-23)$ & $145(122-204)$ & $247(189-304)$ \\
\hline
\end{tabular}

HBGV of $1000 \mathrm{ng} / \mathrm{kg}$ bw per day, which was also true for the upper limit of the 95\% confidence interval around the P95. For fumonisins sum, fumonisin $\mathrm{B}_{4}$ was not included in our calculations. EFSA evaluated the four forms of fumonisin in 2018 (EFSA, 2018a). Only very limited information on the occurrence of fumonisin $\mathrm{B}_{4}$ was available at that time, and no ratio was derived for the concentration of this mycotoxin to the other forms. Fumonisin $\mathrm{B}_{4}$ was also not included in the Dutch TDS of 2013 (López et al., 2016) and in the most recent evaluation of fumonisins by the FAO/WHO Joint Meeting on Food additives (JECFA, 2018).

Exposure to mycotoxins was calculated using the OIM model. This model is commonly used by EFSA to calculate the long-term exposure to mycotoxins (e.g. EFSA, 2020b,d), environmental contaminants (e.g. EFSA, 2020c,f) and food additives (e.g. EFSA, 2020a,e), and to calculate the chronic cumulative exposure to groups of pesticides (EFSA, 2020g). Using this model, it is assumed that the average exposure over the available consumption days for each person, in our case two days, is a good estimate of the long-term exposure. Given the limited number of person-days present in a food consumption database per person and the variation in daily food consumption by an individual, the distribution of mean intakes per individual obtained with OIM will often be too wide in comparison to distributions of 'true' long-term intakes per person (Goedhart et al., 2012). Due to this, P95 exposure estimates may be overestimated. However, we do not expect that this has affected the results of the risk characterisation of the five critical mycotoxins, considering the extent to which the P95 estimates exceeded the HBGVs and the magnitude of the MOEs (Table 5).
Our TDS was based on food consumption data from the first two years of the DNFCS 2012-2016 and exposure was estimated using the data for the period 2012-2016. The 2012-2016 period includes a larger group of children $(n=440$ compared to $n=232)$ and is more representative due to the inclusion of food consumption data of two more recent years. Exposure to mycotoxins for the whole period (2012-2016) did not differ from that for the first two years of the DNFCS; all 2012-2014-estimates were within the 95\% confidence interval of the 2012-2016-estimates (data not shown). The only exception was the P95 intake of citrinin for the oldest age group. This difference was due to a higher consumption of fish in the 2012-2016 period. However, the two main fish-based foods consumed in the 2012-2016 period were the same as in the 2012-2014 period, namely fish fingers and salmon.

\section{Exposure of children to mycotoxins}

Several total diet studies (TDSs) in Europe have looked at the dietary exposure to mycotoxins in children: TDSs in Czech Republic (Ostry et al., 2020), France (Vin et al., 2020), Ireland (FSAI, 2016) and the Netherlands (Sprong et $a l ., 2016)$. An overview of the exposure results for the five mycotoxins that may raise health concerns in our TDS (see Results - comparison with HBGV or calculation of MOE) is presented in Table 7. In all these studies, exposure was calculated according to an LB and UB scenario. Comparing our MB estimates for the 1- and 2-year olds to the reported UB estimates showed that especially the high exposure to alternariol monomethyl ether, ochratoxin A and T-2/HT-2 sum in our study exceeded the high exposure estimates in 
the other TDSs, even when taking into consideration that high exposures could refer to different percentiles (P90, P95 or P97.5) and that these were UB estimates (Table 7). On the other hand, our high MB exposure estimate for alternariol was lower than reported in the French TDS among 1- and 2-year olds. These differences were partly due to differences in analysed concentrations. For example, concentrations of alternariol and alternariol monomethyl ether were all below the LOD in the French study, whereas in our study a high number of composite samples had an analysed concentration above the LOD (Supplementary Table S7). In both cases, the French UB estimate was due to substituting all analysed composite samples with the LOD. Another example is the lower exposure to T-2/HT-2 sum in the Czech TDS, because only the exposure via grainbased foods was considered in the Czech TDS. As shown in our TDS, exposure to these toxins was mainly due to their presence in juices (Table 4).

The European Food Safety Authority (EFSA) also calculated the exposure to mycotoxins in Europe. In these calculations, individual food consumption data of European countries were combined with a merged dataset of analytical levels of mycotoxins in foods mainly from European Member States. For the five critical mycotoxins, the LB and UB P50 and P95 exposure estimates calculated by EFSA for children of 1 and 2 years across European dietary surveys are listed in Table 7. Comparing our MB P95 estimates to the UB P95 estimates showed that our estimates exceeded the UB P95 estimates for alternariol monomethyl ether and T-2/HT-2 sum. For both mycotoxins, grain-based foods contributed most to the exposure in the EFSA calculations (EFSA, 2016b, 2017c), whereas in our calculations fruit juices contributed largely to the exposure. For the other estimates, our MB estimates were between the LB and UB exposure estimate (Table 7).

We noted that some mycotoxins were detected in foods and beverages where they were not expected or known to occur. These occurrences included ergot alkaloids in cheese, ochratoxin A in follow-on formula, T-2/HT-2 sum in fruit juice and zearalenone in chocolate (Supplementary Table S5). For example, European Member States reported on concentrations of ergot alkaloids in only grain-based products (EFSA, 2012b), and concentrations of ochratoxin A reported in follow-on formula were all below the LOD or LOQ (EFSA, 2020b).

Foods and beverages included in the TDS were sampled from August to November 2017. Presence and concentrations of mycotoxins in (ingredients of) foods and beverages is often dependent on weather and storage conditions that can vary between seasons and years, hampering the comparison of exposure estimates between different studies (Table 7).
The calculated exposures are only representative for the presence of mycotoxins in foods and beverages during the time of sampling. Additionally, foods and beverages were sampled in one area in the Netherlands, namely Wageningen and surroundings. Most foods and beverages were bought in supermarkets with a nation-wide coverage. Specialty stores, such as greengrocers and bakers, source their products or raw materials from only a few auctions or wholesalers in the Netherlands. Therefore, this study can be considered as representative for Dutch 1- and 2-year old children.

\section{Risk characterisation of mycotoxins}

For five mycotoxins, a possible health risk could not be excluded (Table 5). The effects on which the HBGVs and BMDLs are based occur after a 'lifelong' period of exposure (Table 2). Exceeding the HBGV or having an insufficient MOE during a limited time period, such as early childhood, may therefore not necessarily lead to adverse health effects. However, a health concern for exposure estimates of $\mathrm{AFB}_{1}$, the two Alternaria toxins, ochratoxin A and T-2/HT-2 sum could also not be excluded for persons 2-79 years of age in the Dutch TDS of 2013 (Sprong et al., 2016). Hence, it cannot be excluded that the children of the current TDS may also have a high exposure to these mycotoxins in later life.

Toxicity related to three mycotoxins with a high exposure is uncertain. For the two Alternaria toxins, a threshold of toxicological concern (TTC) of $2.5 \mathrm{ng} / \mathrm{kg}$ bw per day was derived by EFSA (EFSA, 2011a). A TTC was derived because there were few or no relevant toxicity data on these toxins. As discussed in Sprong et al. (2016), the toxicological characteristics of both toxins need to be clarified further to assess the health risk related to their exposure. This is especially relevant, considering that these toxins were found in a large number of composite samples with a detectable concentration in our TDS (see Results - concentrations of mycotoxins in composite samples). For ochratoxin A, it is uncertain whether a minimum value of 10,000 is appropriate for the $\mathrm{BMDL}_{10}$ for increased incidence of kidney tumours (EFSA, 2020b). An MOE of 10,000 is used for chemicals that are both genotoxic (causing DNA damage) and carcinogenic (EFSA, 2005). EFSA could not determine whether ochratoxin A causes cancer via interaction with DNA and concluded that toxicity studies are required to elucidate this.

For beauvericin, enniatin $B$ and enniatin $B_{1}$, no HBGVs or BMDLs are available and it was not possible to determine whether the exposure was (too) high. Concentrations of these mycotoxins were detected in several composite samples (Supplementary Table S5). 
Table 7. Overview of exposure estimates ${ }^{1}$ of five mycotoxins that may pose a health risk in children of 1 and 2 years of age in the Netherlands from total diet studies in Europe and the most recent EFSA opinions. ${ }^{2}$

\begin{tabular}{|c|c|c|c|c|c|c|}
\hline \multirow[t]{2}{*}{ Mycotoxin } & \multirow[t]{2}{*}{ Country } & \multirow[t]{2}{*}{ Year of sampling } & \multirow{2}{*}{$\begin{array}{l}\text { Age group } \\
\text { (years) }\end{array}$} & Mean or $\mathrm{P} 50^{3}$ & High (P90, P95 or $\mathrm{P} 97.5)^{3}$ & \multirow[t]{2}{*}{ Reference } \\
\hline & & & & \multicolumn{2}{|c|}{ in ng/kg body weight per day } & \\
\hline \multirow[t]{5}{*}{ AFLs sum } & The Netherlands & 2013 & $2-6$ & $0(\mathrm{LB})-3.6(\mathrm{UB})^{4}$ & $0.1(\mathrm{LB})-6.3(\mathrm{UB})^{5}$ & Sprong et al., 2016 \\
\hline & France & 2011-2012 & $1-2^{9}$ & $0(\mathrm{LB})-2.6(\mathrm{UB})^{6}$ & $0(\mathrm{LB})-8.3(\mathrm{UB})^{7}$ & Vin et al., 2020 \\
\hline & Ireland & 2012 & $5-12$ & $0.6(\mathrm{LB})-6.8(\mathrm{UB})^{6}$ & $1.5(\mathrm{LB})-13(\mathrm{UB})^{8}$ & FSAl, 2016 \\
\hline & Europe & 2013-2018 & $1-2^{10}$ & $1.2(\mathrm{LB})-9.1(\mathrm{UB})^{6}$ & $2.3(\mathrm{LB})-15(\mathrm{UB})^{5}$ & EFSA, 2020d \\
\hline & The Netherlands & 2017 & $1-2$ & $3.6(\mathrm{MB})^{4}$ & $6.4(\mathrm{MB})^{5}$ & Our study \\
\hline \multirow[t]{4}{*}{$\mathrm{AOH}$} & The Netherlands & 2013 & $2-6$ & $7.3(\mathrm{LB})$ - $19(\mathrm{UB})^{4}$ & $19(\mathrm{LB})-45(\mathrm{UB})^{5}$ & Sprong et al., 2016 \\
\hline & France & 2011-2012 & $1-2^{9}$ & $0(\mathrm{LB})-75(\mathrm{UB})^{6}$ & $0(\mathrm{LB})-238(\mathrm{UB})^{7}$ & Vin et al., 2020 \\
\hline & Europe & $2010-2015$ & $1-2^{10}$ & $3.8(\mathrm{LB})-72(\mathrm{UB})^{6}$ & $11(\mathrm{LB})-271(\mathrm{UB})^{5}$ & EFSA, 2016b \\
\hline & The Netherlands & 2017 & $1-2$ & $14(\mathrm{MB})^{4}$ & $42(M B)^{5}$ & Our study \\
\hline \multirow[t]{4}{*}{ AME } & The Netherlands & 2013 & $2-6$ & $4.9(\mathrm{LB})-29(\mathrm{UB})^{4}$ & $21(\mathrm{LB})-56(\mathrm{UB})^{5}$ & Sprong et al., 2016 \\
\hline & France & 2011-2012 & $1-2^{9}$ & $0(\mathrm{LB})-11(\mathrm{UB})^{6}$ & $0(\mathrm{LB})-23(\mathrm{UB})^{7}$ & Vin et al., 2020 \\
\hline & Europe & $2010-2015$ & $1-2^{10}$ & $3.4(\mathrm{LB})-39(\mathrm{UB})^{6}$ & $10(\mathrm{LB})-97(\mathrm{UB})^{5}$ & EFSA, 2016b \\
\hline & The Netherlands & 2017 & $1-2$ & $21(\mathrm{MB})^{4}$ & $123(\mathrm{MB})^{5}$ & Our study \\
\hline \multirow[t]{5}{*}{ OTA } & The Netherlands & 2013 & $2-6$ & $0.4(\mathrm{LB})-4.4(\mathrm{UB})^{4}$ & $1.5(\mathrm{LB})-8.8(\mathrm{UB})^{5}$ & Sprong et al., 2016 \\
\hline & France & 2011-2012 & $1-2^{9}$ & $0(\mathrm{LB})-2.9(\mathrm{UB})^{6}$ & $0(\mathrm{LB})-5.0(\mathrm{UB})^{7}$ & Vin et al., 2020 \\
\hline & Ireland & 2012 & $5-12$ & $1.2(\mathrm{LB})-2.3(\mathrm{UB})^{6}$ & $2.3(\mathrm{LB})-4.7(\mathrm{UB})^{8}$ & FSAl, 2016 \\
\hline & Europe & $2009-2018$ & $1-2^{10}$ & $3.3(\mathrm{LB})-18(\mathrm{UB})^{6}$ & $10(\mathrm{LB})-37(\mathrm{UB})^{5}$ & EFSA, 2020b \\
\hline & The Netherlands & 2017 & $1-2$ & $4.7(\mathrm{MB})^{4}$ & $22(\mathrm{MB})^{5}$ & Our study \\
\hline \multirow[t]{5}{*}{ T-2/HT-2 sum } & The Netherlands & 2013 & $2-6$ & $14(\mathrm{LB})$ - $47(\mathrm{UB})^{4}$ & $212(\mathrm{LB})-403(\mathrm{UB})^{5}$ & Sprong et al., 2016 \\
\hline & France & 2011-2012 & $1-2^{9}$ & $0.8(\mathrm{LB})-169(\mathrm{UB})^{6}$ & $0(\mathrm{LB})-235(\mathrm{UB})^{7}$ & Vin et al., 2020 \\
\hline & Czech Republic & $2016-2017$ & $4-6$ & $1.8(\mathrm{LB})-8.2(\mathrm{UB})^{6}$ & $6.5(\mathrm{LB})-31(\mathrm{UB})^{5}$ & Ostry et al., 2020 \\
\hline & Europe & $2011-2016$ & $1-2^{10}$ & $9.0(\mathrm{LB})-65(\mathrm{UB})^{6}$ & $24(\mathrm{LB})-109(\mathrm{UB})^{5}$ & EFSA, 2017c \\
\hline & The Netherlands & 2017 & $1-2$ & $18(\mathrm{MB})^{4}$ & $247(M B)^{5}$ & Our study \\
\hline \multicolumn{7}{|c|}{$\begin{array}{l}{ }^{1} \text { Exposure estimates up to } 9.4 \mathrm{ng} / \mathrm{kg} \text { body weight per day were rounded up to one decimal point, and those higher than or equal to } 9.5 \mathrm{ng} / \mathrm{kg} \text { body weight } \\
\text { per day were rounded up to the nearest whole number. }\end{array}$} \\
\hline \multicolumn{7}{|c|}{ 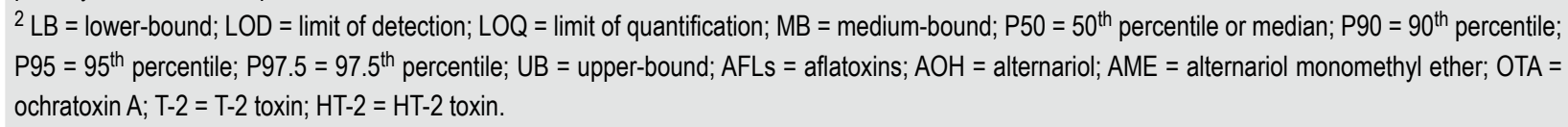 } \\
\hline \multirow{2}{*}{\multicolumn{7}{|c|}{$\begin{array}{l}{ }^{3} \text { Ranges refer to LB and UB estimates of exposure. For the LB estimate, concentrations below the LOD or the LOQ were substituted a zero value. } \\
\text { For the UB estimate, these concentrations were substituted a value equal to the LOD or the LOQ. }\end{array}$}} \\
\hline & & & & & & \\
\hline \multicolumn{7}{|c|}{${ }^{4}$ P50. } \\
\hline \multicolumn{7}{|l|}{5 P95. } \\
\hline \multicolumn{7}{|l|}{${ }^{6}$ Mean. } \\
\hline \multicolumn{7}{|l|}{7 p9o. } \\
\hline \multicolumn{7}{|l|}{8 P97.5. } \\
\hline \multicolumn{7}{|c|}{${ }^{9}$ Range of lowest LB and highest UB exposure estimate for children aged 1-4, 5-6, 7-12 and 13-36 months. } \\
\hline & & & & 2 years of age across $E$ & & \\
\hline
\end{tabular}

\section{Conclusions}

Dietary exposure to aflatoxins, Alternaria toxins, ochratoxin A and T-2/HT-2 sum may pose health concerns for 1- and 2-year old children in the Netherlands. Main contributors to the exposure to these mycotoxins were 'bread', 'biscuits', 'breakfast cereals,' 'other juices,' 'chocolates', 'dried fruits', 'follow-on formula' and 'apple juice'. Toxicological characteristics of the Alternaria toxins need to be clarified, considering that these toxins had a detectable concentration in a high number of composite samples. This is also true for beauvericin, enniatin $B$ and enniatin $B 1$ for which no HBGVs or BMDLs are available. 


\section{Supplementary material}

Supplementary material can be found online at https://doi. org/10.3920/wmj2020.2676.

Materials and methods S1. Description of analytical methods to determine mycotoxin concentrations in the composite samples.

Table S1. Mass spectrometer settings for the multimycotoxin method in $\mathrm{ESI}^{-}$ionization mode.

Table S2. Mass spectrometer settings for the multimycotoxin method in $\mathrm{ESI}^{+}$ionization mode.

Table S3. Mass spectrometer settings for the detection of trichothecenes by GC-MS/MS.

Table S4. Limits of detection and quantification (in $\mu \mathrm{g} / \mathrm{kg}$ analysis material, freeze-dried where applicable or in liquid form, for others) of the methods used for the analysis of mycotoxins in the relevant food subgroups.

Table S5. Individual concentrations of mycotoxins in $\mu \mathrm{g} /$ $\mathrm{kg}$ fresh material (recalculated from freeze-dried where applicable) in the composite samples in which at least one of the mycotoxins had a concentration above the limit of detection.

Table S6. Composite samples included in the exposure calculations using concentrations analysed above the limit of detection and values equal to half the limit of detection.

Table S7. Minimum and maximum concentrations of mycotoxins in the composite samples per food group included in the exposure assessment.

\section{Conflict of interest}

The authors declare no conflict of interest.

\section{Acknowledgements}

Authors gratefully acknowledge the Dutch Ministry of Agriculture, Nature and Food Quality for financial support.

\section{References}

De Boer, W.J., Kruisselbrink, J. and Van Lenthe, M., 2019. MCRA 8.3 a web-based program for Monte Carlo Risk Assessment. Reference manual. Biometris, Wageningen UR, Wageningen, the Netherlands.

Efron, B. and Tibshirani, R., 1993. An introduction to the bootstrap. Monographs on statistics and applied probability. Chapman \& Hall, New York, NY, USA.

Efron, B., 1979. Bootstrap methods: another look at the Jackknife. Annals of Statistics 7: 1-26.
European Food Safety Authority (EFSA), 2005. Opinion of the Scientific Committee on a request from EFSA related to a harmonised approach for risk assessment of substances which are both genotoxic and carcinogenic. EFSA Journal 3: 282. https://doi.org/10.2903/j. efsa.2005.282.

European Food Safety Authority (EFSA), 2011a. Scientific Opinion on the risks for animal and public health related to the presence of Alternaria toxins in feed and food. EFSA Journal 9: 2407. https:// doi.org/10.2903/j.efsa.2011.2407

European Food Safety Authority (EFSA), 2011b. Scientific Opinion on the risks for public health related to the presence of zearalenone in food. EFSA Journal 9: 2197. https://doi.org/10.2903/2011.2197

European Food Safety Authority (EFSA), 2011c. Towards a harmonised Total Diet Study approach: a guidance document. EFSA Journal 9: 2450. https://doi.org/10.2903/j.efsa.2011.2450

European Food Safety Authority (EFSA), 2012a. Guidance on the use of probabilistic methodology for modelling dietary exposure to pesticide residues. EFSA Journal 10: 2839. https://doi.org/10.2903/j. efsa.2012.2839

European Food Safety Authority (EFSA), 2012b. Scientific Opinion on ergot alkaloids in food and feed. EFSA Journal 10: 2798. https:// doi.org/10.2903/j.efsa.2012.2798

European Food Safety Authority (EFSA), 2012c. Scientific Opinion on the risks for public and animal health related to the presence of citrinin in food and feed. EFSA Journal 10: 2605. https://doi. org/10.2903/j.efsa.2012.2605

European Food Safety Authority (EFSA), 2013a. Scientific Opinion on risks for animal and public health related to the presence of modified forms of nivalenol in food and feed. EFSA Journal 11: 3262. https://doi.org/10.2903/j.efsa.2013.3262

European Food Safety Authority (EFSA), 2013b. Scientific Opinion on the risk for public and animal health related to the presence of sterigmatocystin in food and feed. EFSA Journal 11: 3254. https:// doi.org/10.2903/j.efsa.2013.3254

European Food Safety Authority (EFSA), 2014. Scientific Opinion on the risks to human and animal health related to the presence of beauvericin and enniatins in food and feed. EFSA Journal 12: 3802. https://doi.org/10.2903/j.efsa.2014.3802

European Food Safety Authority (EFSA), 2016a. Appropriateness to set a group health-based guidance value for zearalenone and its modified forms. EFSA Journal 14: 4425. https://doi.org/10.2903/j. efsa.2016.4425

European Food Safety Authority (EFSA), 2016b. Scientific report on the dietary exposure assessment to Alternaria toxins in the European population. EFSA Journal 14: 4654. https://doi.org/10.2903/j. efsa.2016.4654

European Food Safety Authority (EFSA), 2017a. Appropriateness to set a group health based guidance value for nivalenol and its modified forms. EFSA Journal 15: 4751. https://doi.org/10.2903/j. efsa.2017.4751

European Food Safety Authority (EFSA), 2017b. Risks for animal health related to the presence of zearalenone and its modified forms in feed. EFSA Journal 15: 4851. https://doi.org/10.2903/j.efsa.2017.4851 
European Food Safety Authority (EFSA), 2017c. Scientific Opinion on the appropriateness to set a group health-based guidance value for T2 and HT2 toxin and its modified forms. EFSA Journal 15: 4655. https://doi.org/10.2903/j.efsa.2017.4655

European Food Safety Authority (EFSA), 2017d. Scientific Opinion on the risks to human and animal health related to the presence of deoxynivalenol and its acetylated and modified forms in food and feed. EFSA Journal 15: 4718. https://doi.org/10.2903/j.efsa.2017.4718

European Food Safety Authority (EFSA), 2017e. Scientific report on human and animal dietary exposure to T-2 and HT-2 toxin. EFSA Journal 15: 4972. https://doi.org/10.2903/j.efsa.2017.4972

European Food Safety Authority (EFSA), 2018a. Appropriateness to set a group health-based guidance value for fumonisins and their modified forms. EFSA Journal 16: 5172. https://doi.org/10.2903/j. efsa.2018.5172

European Food Safety Authority (EFSA), 2018b. Guidance on uncertainty analysis in scientific assessments. EFSA Journal 16: 5123. https://doi.org/10.2903/j.efsa.2018.5123

European Food Safety Authority (EFSA), 2020a. Re-evaluation of stearyl tartrate (E 483) as a food additive. EFSA Journal 18: 6033. https://doi.org/10.2903/j.efsa.2020.6033

European Food Safety Authority (EFSA), 2020b. Risk assessment of ochratoxin A in food. EFSA Journal 18: 6113. https://doi. org/10.2903/j.efsa.2020.6113

European Food Safety Authority (EFSA), 2020c. Scientic Opinion on the update of the risk assessment of nickel in food and drinking water. EFSA Journal 18: 6268. https://doi.org/10.2903/j.efsa.2020.6268

European Food Safety Authority (EFSA), 2020d. Scientific opinion risk assessment of aflatoxins in food. EFSA Journal 18: 6040. https:// doi.org/10.2903/j.efsa.2020.6040

European Food Safety Authority (EFSA), 2020e. Scientific Opinion on the re-evaluation of dimethyl polysiloxane (E 900) as a food additive. EFSA Journal 18: 6107. https://doi.org/10.2903/j.efsa.2020.6107

European Food Safety Authority (EFSA), 2020f. Scientific Opinion on the risk to human health related to the presence of perfluoroalkyl substances in food. EFSA Journal 18: 6223. https://doi.org/10.2903/j. efsa.2020.6223

European Food Safety Authority (EFSA), 2020g. Scientific report on the cumulative dietary risk characterisation of pesticides that have chronic effects on the thyroid. EFSA Journal 18: 6088. https://doi. org/10.2903/j.efsa.2020.6088

Food Safety Authority of Ireland (FSAI), 2016. Report on a total diet study carried out by the Food Saferty Authority of Ireland in the period 2012-2014. FSAI, Dublin, Ireland.
Goedhart, P.W., Van der Voet, H., Knüppel, S., Dekkers, A.L.M., Dodd, K.W., Boeing, H. and Van Klaveren, J.D., 2012. A comparison by simulation of different methods to estimate the usual intake distribution for episodically consumed foods. EFSA Supporting Publications 9: 299e. https://doi.org/10.2903/sp.efsa.2012.EN-299 Joint FAO/WHO Expert Committee on Food Additives (JECFA), 1995. Evaluations of certain food additives and contaminants (Fortyfourth report of the Joint FAO/WHO Expert Committee on Food Additives). WHO Technical Report Series, No. 859. World Health Organisation, Geneva, Switzerland.

Joint FAO/WHO Expert Committee on Food Additives (JECFA), 2018. Safety evaluation of certain contaminants in food: prepared by the eighty-third meeting of the Joint FAO/WHO Expert Committee on Food Additives. World Health Organisation, Geneva, Switzerland.

López, P., De Rijk, T., Sprong, R.C., Mengelers, M.J.B., Castenmiller, J.J.M. and Alewijn, M., 2016. A mycotoxin-dedicated total diet study in the Netherlands in 2013: Part II - occurrence. World Mycotoxin Journal 9: 89-108. https://doi.org/10.3920/wmj2015.1906

Ostry, V., Dofkova, M., Blahova, J., Malir, F., Kavrik, R., Rehurkova, I. and Ruprich, J., 2020. Dietary exposure assessment of sum deoxynivalenol forms, sum T-2/HT-2 toxins and zearalenone from cereal-based foods and beer. Food and Chemical Toxicology 139: 111280. https://doi.org/10.1016/j.fct.2020.111280

Sprong, R.C., De Wit-Bos, L., Te Biesebeek, J.D., Alewijn, M., Lopez, P. and Mengelers, M.J.B., 2016. A mycotoxin-dedicated total diet study in the Netherlands in 2013: Part III - exposure and risk assessment. World Mycotoxin Journal 9: 109-127. http://dx.doi. org/10.3920/WMJ2015.1905

Van Rossum, C.T.M., Buurma-Rethans, E.J.M., Vennemann, F.B.C., Beukers, M., Brants, M.H.A.M., De Boer, E.J. and Ocké, M.C., 2016. The diet of the Dutch. Results of the first two years of the Dutch National Food Consumption Survey 2012-2016. RIVM Letter report 2016-0082. National Institute for Public Health and the Environment (RIVM), Bilthoven, the Netherlands.

Van Rossum, C.T.M., Buurma-Rethans, J.M., Dinnissen, C.S., Beukers, M.H., Brants, H.A.M., Dekkers, A.L.M. and Ocké, M.C., 2020. The diet of the Dutch. Results of the Dutch National Food Consumption Survey 2012-2016. RIVM report 2020-0083. National Institute for Public Health and the Environment (RIVM), Bilthoven, the Netherlands. https://doi.org/10.21945/RIVM-2020-0083

Vin, K., Rivière, G., Leconte, S., Cravedi, J.-P., Fremy, J.M., Oswald, I.P., Roudot, A.-C., Vasseur, P., Jean, J., Hulin, M. and Sirot, V., 2020. Dietary exposure to mycotoxins in the French infant total diet study. Food and Chemical Toxicology 140: 111301. https:// doi.org/10.1016/j.fct.2020.111301 
